\title{
Research Article \\ Effect of Filler Content on the Performance of Epoxy/PTW Composites
}

\author{
Mudradi Sudheer, Ravikantha Prabhu, Kandavalli Raju, and Thirumaleshwara Bhat \\ Department of Mechanical Engineering, St. Joseph Engineering College, Mangalore, Karnataka 575 028, India \\ Correspondence should be addressed to Mudradi Sudheer; msudheerm2002@yahoo.co.in
}

Received 30 May 2013; Revised 6 February 2014; Accepted 14 March 2014; Published 27 April 2014

Academic Editor: Steve Bull

Copyright ( 2014 Mudradi Sudheer et al. This is an open access article distributed under the Creative Commons Attribution License, which permits unrestricted use, distribution, and reproduction in any medium, provided the original work is properly cited.

\begin{abstract}
This paper presents the mechanical and tribological characteristics of potassium titanate whisker (PTW) reinforced epoxy composites. The effect of various test variables and material parameters on the friction and wear behavior of epoxy/PTW composites has been studied systematically. Tribological tests were conducted on a pin-on-disc apparatus under dry sliding conditions. Addition of PTW was found to improve the wear resistance of the composites and $15 \mathrm{wt} \%$ PTW filled epoxy exhibited lowest specific wear rate and highest friction coefficient compared to other test samples. PTW additions showed beneficiary effect on density, hardness, and stiffness properties of composites; however, strength properties and ductility were found to decrease with the increasing content of PTW. Scanning electron microscope (SEM) images of tensile fractured surfaces and worn-out surfaces of selected samples revealed different fracture mechanisms.
\end{abstract}

\section{Introduction}

Epoxy resin is one of the widely used polymer matrixes in the composite industry, due to its excellent adhesion to many reinforcements. Its high hardness, excellent resistance to humidity, good mechanical and thermal properties coupled with processability must also be highlighted [1]. One of the key issues addressed in the polymer industry is to further modify the performance of epoxy resin by adding different fillers. Discontinuous reinforcements which include particulates, whiskers, and short fibers have recently gained significant attention, since along with the improvement in the properties, discontinuously reinforced composites can be easily processed and subjected to various secondary operations such as turning, drilling, and milling [2]. The end properties of the composite depend not only on the matrix but also on the reinforcement and type of the interface between them. The reinforcement, depending on material composition, its volume, size, shape, and surface modification, can affect many properties including strength, hardness, wear resistance, heat dissipation, and dimensional stability.

Several researchers have explored the possibility of modifying the behaviour of thermoset epoxy by reinforcing it with different types of fillers. Hard ceramics such as boron carbide $\left(\mathrm{B}_{4} \mathrm{C}\right)$, silicon carbide $(\mathrm{SiC})$, and alumina $\left(\mathrm{Al}_{2} \mathrm{O}_{3}\right)$ are found to enhance mechanical and/or wear properties of epoxy [35]. The soft or lubricant fillers such as graphite, molybdenum sulphide $\left(\mathrm{MoS}_{2}\right)$, and polytetrafluoroethylene (PTFE) are sometimes employed as filler for epoxy to make them suitable for low friction and low wear environments $[4,6,7]$. To enhance the interfacial interaction between the filler and the matrix, fillers are subjected to different pretreatments. Such attempts are found to improve the mechanical and tribological properties of composites. The experimental results by Shi et al. [5] indicated that incorporation of nano- $\mathrm{Al}_{2} \mathrm{O}_{3}$ particles leads to increased flexural modulus and flexural strength of epoxy. The dry sliding against steel disc designated that frictional coefficient and wear rate of epoxy can be reduced at rather low concentration of nano- $\mathrm{Al}_{2} \mathrm{O}_{3}$, and the pretreatments of the particles further gave play to this favorable effect. Ji et al. [8] found that very small filler content of $0.2 \mathrm{vol} \%$ of nanosized $\mathrm{SiC}$ particles pretreated by graft polymerization of polyacrylamide effectively reduced the friction coefficient and wear rate of epoxy even under high contact pressures. Rodrigues and Broughton [9] have observed improvement in flexural and tensile strengths ranging between $24 \%$ and 
$56 \%$ in case of silane treated $\mathrm{B}_{4} \mathrm{C}$ filled epoxy composites. Among the different pretreatments for reinforcements, silane coupling agents have been widely employed to enhance the adhesion between polymer and inorganic fillers [10]. Silane functionalization of different fillers is also found to improve the performance of filled epoxy composites [11, 12].

Whiskers are short fiber-shaped single crystals with high perfection and very large length-to-diameter ratios. Owing to their small diameter, whiskers are almost free of defects and thus present a resistance very close to the maximum theoretical value expected from the elasticity theory. In general, ceramic whiskers display high aspect ratio and many important properties such as low density, low coefficient of thermal expansion, high strength and modulus, high melting point, and excellent resistance to chemical attack. Thus these whiskers are chiefly employed as reinforcing material in polymer composites and are very attractive materials as components of composites [13]. Among the available ceramic whiskers, potassium titanate whisker $\left(\mathrm{K}_{2} \mathrm{O} \cdot 6 \mathrm{TiO}_{2}\right.$, PTW $)$ has been found to be a promising reinforcer for the wear resistant composites due to its unique properties, such as outstanding mechanical performance, low hardness (Mohs hardness 4), and excellent chemical stability. PTW exhibits thermal durability, chemical resistivity, and dispersibility and has been useful as reinforcement for plastics, ceramics, and heat-insulating paints, as ion exchange materials and photocatalysts, and as substitutes of asbestos. The price of the PTW ranges from one-tenth to one-twentieth of the cost of SiC whiskers [14].

Many attempts have been made to modify the mechanical and tribological properties of different polymers by reinforcing it with PTW as filler. Zhu et al. [15] compared the effect of various whiskers (magnesium borate, calcium sulfate, and PTW) on the performance of nonmetallic (phenolic resin based) friction materials and observed that PTW imparted highest wear resistance to the composite. Kim et al. [16] revealed the effect of filler morphology on the dry sliding performance of novolac resin based composites. They concluded that whisker (PTW) filled matrix resin exhibited smooth frictional behavior and better wear resistance than particulate (barite) filled resin composites. In another study on morphological effects Cho et al. [17] studied the tribological characteristics of nonmetallic brake friction materials containing different shapes of PTW and observed that friction material with splinter shape PTW showed better friction stability and improved wear resistance compared to those containing needle shape PTW and platelet shape PTW materials. While evaluating the mechanical performance, Feng et al. [18] observed that small size PTW (diameter $0.77 \mu \mathrm{m}$ and length $10.47 \mu \mathrm{m}$ ) at intermediate volume fraction of $5 \mathrm{wt} \%$ had improved tensile strength, elongation to break, notched impact strength, and thermal deformation temperature by $35.6,46,3$, and $11 \%$ over PTFE, respectively. When the filler size was increased in their study, mechanical properties such as tensile strength, elongation, and hardness were found to deteriorate. However, the dry friction tests showed that larger size PTW (diameter $1.86 \mu \mathrm{m}$ and length $10.47 \mu \mathrm{m}$ ) performed better and improved the wear resistance of composites at the same whisker content $(5 \mathrm{wt} \%)$. In line with these

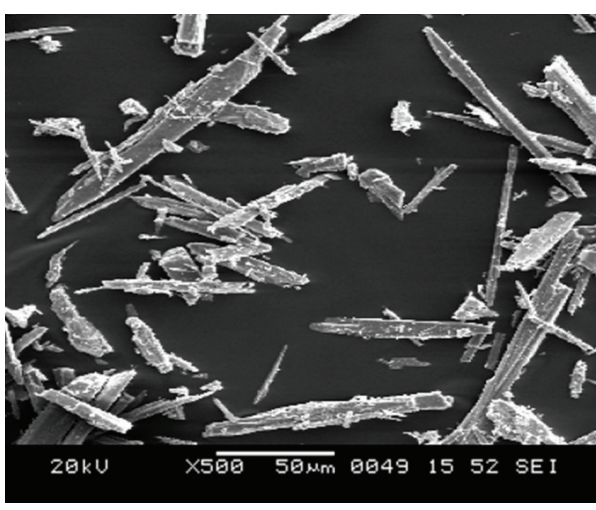

FIgURE 1: SEM picture of PTW whiskers.

observations, Abenojar et al. [3] also noted that larger sized $(23 \mu \mathrm{m}) \mathrm{B}_{4} \mathrm{C}$ particles in small content $(6 \mathrm{wt} \%)$ in epoxy have resulted in lesser wear rate $\left(11 \pm 1 \times 10^{-4} \mathrm{~mm}^{3} / \mathrm{Nm}\right)$ compared to small sized particles $(7 \mu \mathrm{m})$ at the same weight percent of the filler. However, opposite effect was observed when the $\mathrm{B}_{4} \mathrm{C}$ particle size was increased. These studies also indicate that size and content of fillers play a major role in deciding the properties of composites. Chen et al. [19] systematically evaluated the tensile strength of a series of PTW filled castor oil-based polyurethane/epoxy resin interpenetrating polymer networks and found an optimum increase in the tensile strength $(25.5 \mathrm{MPa})$ of the composites at $3 \%$ of PTW.

Even though several reports are available on PTW filled polymer composites, a systematic study dealing with the use of PTW as filler for epoxy resin has not been performed. Therefore the main objective of this study is the addition of different amounts of PTW to epoxy resin and specifically analyzing mechanical and dry sliding wear behaviour of developed composites.

\section{Experimental Details}

2.1. Materials. Room temperature curing epoxy resin (LY 556) belonging to the diglycidyl ether of bisphenol A (DGEBA) family along with the amino based hardener (HY951) was used as the matrix material. These were supplied by Huntsman Advanced Materials India Pvt., Ltd., Bengaluru, India. The reinforcement ceramic used was potassium titanate whiskers and were supplied by Hangzhou Dayangchem Co., Ltd., Hong Kong. These ceramic whiskers were of splinter shape as observed under SEM (Figure 1) with high length/diameter ratio (20-40) and, physicomechanical properties are listed in Table 1. EDAX analysis was used to ascertain approximate chemical composition of whiskers. Figure 2 indicates the spectrum of PTW filler with peaks of oxygen, potassium, and titanium. EDAX elemental analysis indicated in Table 2 confirms the presence of potassium and titanium precipitates.

2.2. Fabrication of Composites. Epoxy/PTW composites are developed by simple mechanical stirring and vacuum assisted 
TABLE 1: Physicomechanical properties of potassium titanate whiskers.

\begin{tabular}{lccccc}
\hline Diameter $(\mu \mathrm{m})$ & Length $(\mu \mathrm{m})$ & Density $(\mathrm{g} / \mathrm{cc})$ & Tensile strength $(\mathrm{GPa})$ & Tensile modulus $(\mathrm{GPa})$ & Hardness $(\mathrm{Mohs})$ \\
\hline $0.5-2.5$ & $10-100$ & 3.185 & 7 & 280 & 4 \\
\hline
\end{tabular}

TABLE 2: Elemental mapping of PTW filler.

\begin{tabular}{lccc}
\hline Element & $(\mathrm{keV})$ & Mass $(\%)$ & At $(\%)$ \\
\hline $\mathrm{O}$ & 0.525 & 45.40 & 70.42 \\
$\mathrm{~K}$ & 3.312 & 11.20 & 7.10 \\
$\mathrm{Ti}$ & 4.508 & 43.40 & 22.48 \\
\hline Total & & 100.00 & 100.00 \\
\hline
\end{tabular}

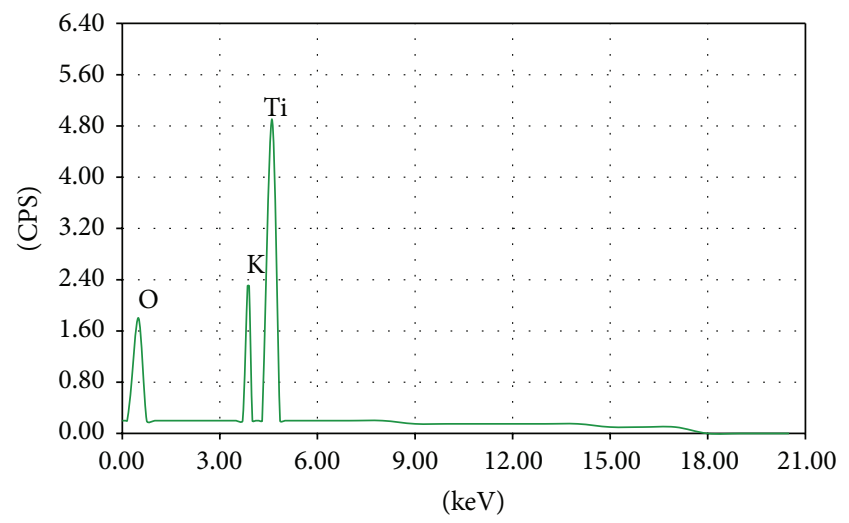

Figure 2: EDAX spectrum of PTW filler.

casting technique. The content of PTW by weight was varied from 0 to $15 \%$ in steps of $5 \%$. The detailed procedure for fabrication of composites is presented elsewhere [20]. Test samples of various sizes for mechanical and tribological characterization were prepared from the cast composites using the diamond tipped cutter. Materials fabricated are thus designated as EP0, EP5, EP10, and EP15; the numerals in the designation indicate the weight percentage of the whiskers, respectively. Figure 3 displays the SEM picture of $15 \%$ PTW filled epoxy. It is visible that the microwhiskers are well distributed in the resin and have good compatibility with the epoxy matrix.

2.3. Mechanical Properties. All mechanical tests were performed under ambient conditions and as per ASTM standards. Test results reported were the average of five repetitive measurements. Densities of the composites were determined using the displacement method as per ASTM D792-13 standard using distilled water as the immersion liquid. Hardness was measured using Rockwell hardness tester (M scale) as per ASTM D785-08. Tensile tests were carried out according to ASTM D3039-08 on a universal testing machine (JJ Lloyd, London, UK, $1-20 \mathrm{kN}$ ) with a cross head speed of $2 \mathrm{~mm} / \mathrm{min}$ and gauge length of $50 \mathrm{~mm}$. Flexural properties were investigated using the same universal testing machine under three point loading conditions with a cross head speed of $2 \mathrm{~mm} / \mathrm{min}$ and gauge length of $50 \mathrm{~mm}$ as per ASTM D790-10.

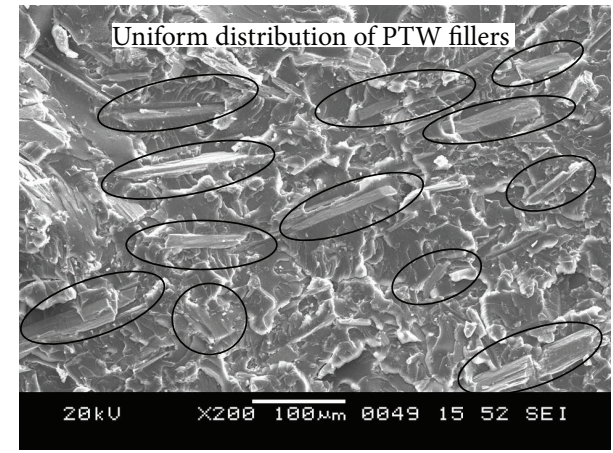

FiguRE 3: SEM picture of 15\% PTW filled epoxy.

Izod impact testing was done on unnotched specimens using pendulum type impact tester (Ceast, maximum capacity $25 \mathrm{~J}$ ) as per ASTM D256-10 to determine the impact strength of developed composites.

2.4. Tribological Properties. Tribological properties of the composites were evaluated under dry sliding conditions using pin on disc test configuration (DUCOM TR 201C, Bengaluru, India) as per ASTM G99-05(2010). Wear test samples of size $10 \times 10 \times 3 \mathrm{~mm}$ were glued to steel pins of $10 \mathrm{~mm}$ square cross section and $30 \mathrm{~mm}$ length and came in contact with (EN31 grade, $62 \mathrm{HRC}$, and $1.6 \mu \mathrm{m} \mathrm{Ra}$ ) carbon steel disc. Prior to testing, the samples were polished against fine grade sand paper (1200 grit $\mathrm{SiC}$ ) to ensure proper contact with counterface. Test conditions were normal load, $10 \mathrm{~N}$, $20 \mathrm{~N}$, and $30 \mathrm{~N}$; sliding velocity, $0.5 \mathrm{~m} / \mathrm{s}, 0.75 \mathrm{~m} / \mathrm{s}$, and $1 \mathrm{~m} / \mathrm{s}$; and sliding distance, $500 \mathrm{~m}, 1000 \mathrm{~m}$, and $1500 \mathrm{~m}$. The pin along with the specimen was then weighed in an electronic balance (Shimadzu Japan, AY220, $0.1 \mathrm{mg}$ accuracy). Before and after wear testing, samples were cleaned with acetone to remove wear debris. Three trials were conducted to ensure the repeatability of test data. Weight loss of the test samples gives the measure of sliding wear loss. Volume loss was calculated from measured weight loss using density data of the test specimen. The specific wear rate $\left(W_{s}\right)$ was calculated as per

$$
W_{s}=\frac{\Delta V}{(L \times d)},
$$

where $\Delta V$ is volume loss in $\mathrm{mm}^{3}, L$ is load in Newton, and $d$ is sliding distance in $\mathrm{m}$. In all experimental conditions the wear rate was found to be reproducible within about $10 \%$.

The frictional force (in Newton) was directly measured from the friction monitor. The coefficient of friction (COF) was calculated as per

$$
\mathrm{COF}=\frac{\text { Tangential frictional force }}{\text { Normal load }} .
$$




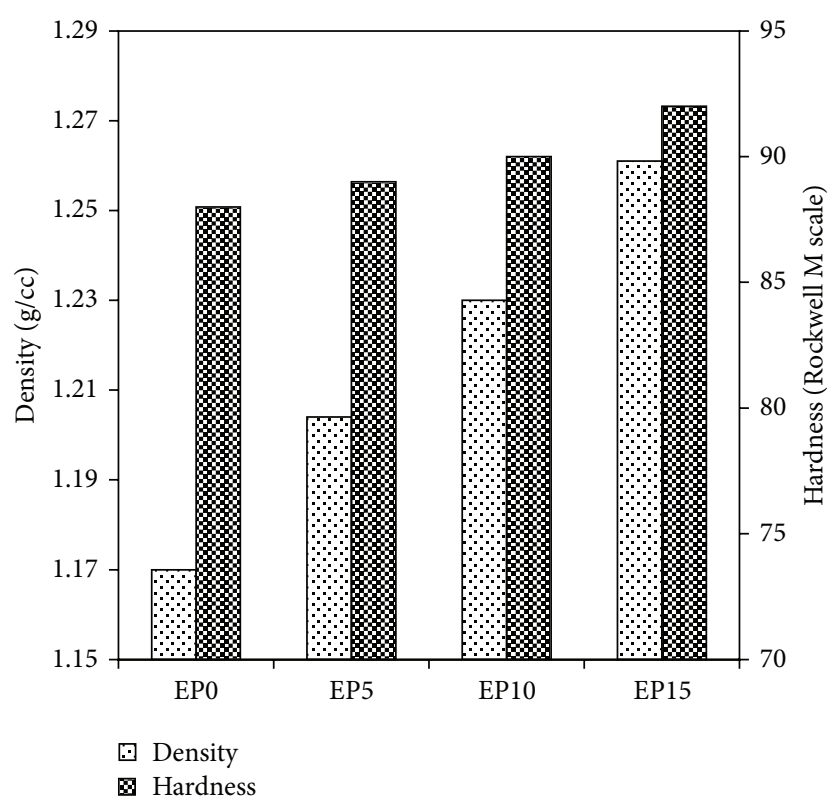

FIGURE 4: Density and hardness of neat epoxy and epoxy/PTW composites.

2.5. Morphological Properties. A scanning electron microscope (Jeol JSM-6380LA, made in Japan) was used to study the tensile fractured surfaces and worn-out surfaces of some selected samples. The sample surfaces were gold coated (Jeol JFC-1600, Auto fine coater) before SEM observation. Worn microstructure of composites has been studied to reveal the effect of maximum testing conditions on dry sliding wear of composites.

\section{Results and Discussion}

\subsection{Mechanical Properties}

3.1.1. Density and Hardness. The effect of PTW contents on density and hardness of neat epoxy is presented in column diagram as shown in Figure 4. It can be observed that both density and hardness of neat epoxy improve gradually with the addition of the whisker content. This is because PTW being the denser and harder phase than epoxy acts to improve the density and hardness properties of the composites. However, improvement reported is only marginal and is about $7 \%$ in density and 5\% in hardness for EP15 composites. Incorporation of whiskers into the polymer matrix increases the cross link density of polymer chains which in turn contributes to improve the hardness. Encouraging aspect of higher hardness is that usually higher composite hardness is accompanied by higher resistance to wear.

3.1.2. Tensile Properties. Tensile properties of the test samples are summarized in the Table 3 and Figure 5 illustrates the stress-strain curve under tensile loading conditions. It can be seen that tensile strength of the neat epoxy is found to decrease with the inclusion of the PTW fillers. A maximum reduction of $20 \%$ in the tensile strength of unmodified

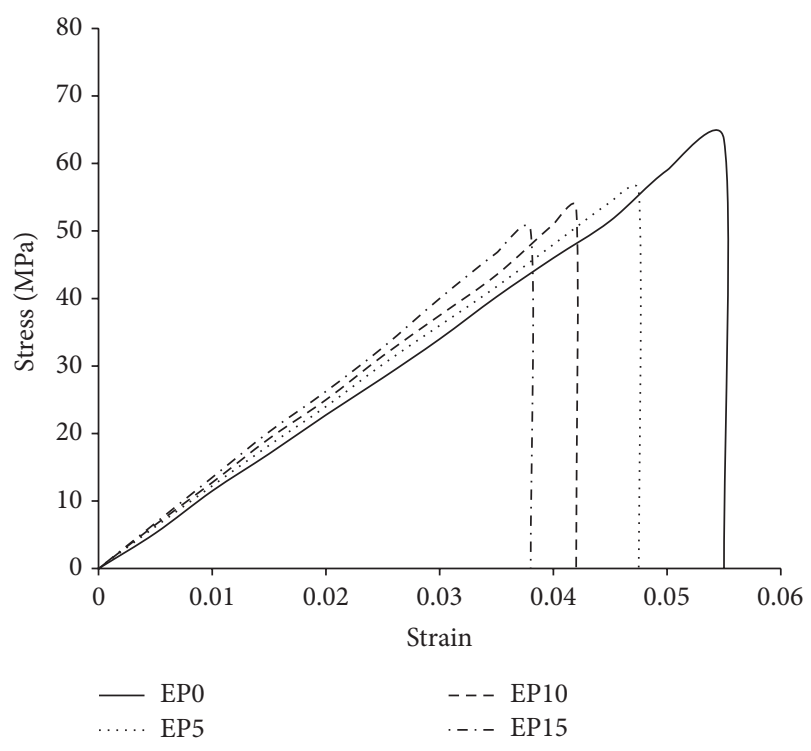

FIGURE 5: Tensile stress-strain curve for test samples.

epoxy is observed for a whisker loading of $15 \mathrm{wt} \%$. These whiskers act as stress concentration sites, leading to the nonuniform stress distribution in the composite and high stresses near the whiskers. During the tensile test, the epoxy matrix around these fillers breaks quickly due to the high stresses, resulting in the decrease in tensile strength of the epoxy/PTW composites. However, it can be noticed that reinforcement of PTW with the epoxy matrix has improved the tensile modulus of the neat polymer. A gain of $41 \%$ in the tensile modulus is observed for EP15 composites. It is understandable that a highly stiffer material such as PTW, when added to relatively softer resin such as epoxy, will contribute to the improvement of the modulus value of the composites.

PTW fillers are found to have detrimental effect on the strain to break. Thus with the addition of whiskers the composite has become more brittle and this resulted in the reduction of percentage elongation of the material. In case of irregularly shaped fillers such as PTW, the strength of the polymer composites usually decreases, as the partially separated microspaces between the whisker and the polymer obstruct the stress transfer from matrix polymer to the filler. This induces increased brittleness in the material during tensile loading conditions. It is well known that PTW fillers are nondeformable solids and thus increase in the whisker loading gives rise to a reduction in the deformable polymer portion in the composite. This obviously will result in reduction in the elongation to break. It follows from Table 3 that the specimens show a monotonic decrease in elongation of about $31 \%$ as the content of PTW in the composite is increased from 0 to $15 \mathrm{wt} \%$. Taha et al. [21] suggested that composite stiffness does not primarily depend on the filler-matrix interface but more likely on the absolute filler content in tensile loading direction, as the tensile modulus is determined as a tangent modulus at low strain values (0.05$0.25 \%)$, where no interfacial debonding is yet assumed to 
TABLE 3: Tensile, flexural, and impact properties of epoxy and epoxy/PTW composites.

\begin{tabular}{lcccccc}
\hline $\begin{array}{l}\text { Material } \\
\text { designation }\end{array}$ & $\begin{array}{c}\text { Tensile strength } \\
(\mathrm{MPa})\end{array}$ & $\begin{array}{c}\text { Tensile modulus } \\
(\mathrm{GPa})\end{array}$ & $\begin{array}{c}\text { Elongation at } \\
\text { break }(\%)\end{array}$ & $\begin{array}{c}\text { Flexural } \\
\text { strength }(\mathrm{MPa})\end{array}$ & $\begin{array}{c}\text { Flexural } \\
\text { modulus }(\mathrm{GPa})\end{array}$ & $\begin{array}{c}\text { Impact strength } \\
(\mathrm{J} / \mathrm{m})\end{array}$ \\
\hline EP0 & $63.9 \pm 1.0$ & $1.77 \pm 0.04$ & $5.48 \pm 0.05$ & $121.1 \pm 2.8$ & $3.72 \pm 0.12$ & $78.33 \pm 1$ \\
EP5 & $56.6 \pm 0.7$ & $1.95 \pm 0.03$ & $4.72 \pm 0.08$ & $111.5 \pm 2.1$ & $4.17 \pm 0.10$ & $75.67 \pm 1$ \\
EP10 & $53.5 \pm 0.4$ & $2.29 \pm 0.02$ & $4.11 \pm 0.08$ & $105.2 \pm 1.3$ & $4.61 \pm 0.10$ & $72.67 \pm 1$ \\
EP15 & $51.2 \pm 0.4$ & $2.49 \pm 0.01$ & $3.78 \pm 0.07$ & $99.4 \pm 1.3$ & $5.35 \pm 0.08$ & $68.33 \pm 1$ \\
\hline
\end{tabular}

occur even in case of poor adhesion. Thus tensile modulus of the epoxy/PTW composites is found to increase even if the strength is reduced. It is common to observe that an improvement in tensile modulus is at the expense of the strain to break, as can be depicted in Table 3 and as cited by several researchers $[3,21]$.

It is worth to note that even though the incorporation of PTW fillers has reduced the tensile strength, it has contributed to the increase of the hardness of neat epoxy. This is mainly because of the difference in loading conditions during testing. During tensile loading conditions, the whisker matrix interface is susceptible to debonding possibly due to poor bond strength between the two. But in case of hardness test, indentation pressure is in action. Thus the epoxy matrix phase and the solid PTW phase would be hardpressed together and touch each other more firmly. Thus the interface is able to transfer the pressure more efficiently even though the interfacial adhesion is poor. This results in the improvement in the hardness. Similar property modification has been previously reported for ceramic particles reinforced polymer matrix composites [22].

3.1.3. Flexural Properties. Similar to tensile properties, the same trend is observed in flexural tests (Table 3). Flexural strength of the microwhisker filled composites is known to be reduced with the rising whisker content. Flexural strength of the EP15 composite is $18 \%$ lesser than that of neat epoxy. However, flexural modulus is found to improve almost linearly with the whisker loading. Maximum increase observed in the flexural stiffness is $44 \%$ when compared to that of neat epoxy. The influence of rigid microfillers on the stress-stain behavior of polymers under flexural loading is well known. Microfillers commonly increase the stiffness, but on the other side they may have a detrimental effect on the strength and strain to break [23]. However, strength properties of the composites can be improved by pretreating the fillers with the suitable agents $[5,9,24]$.

In reinforced polymers, it is common to observe that flexural strengths are higher than tensile strengths. Under a flexural loading situation, rather than acting as stress raisers as is the case in tensile loading, the fillers apparently aid the load bearing capability of a composite. This is due to the fact that compressive stress tends to close cracks and flaws that are perpendicular to the applied stress, opposite to the crack opening mechanism occurring in a tensile strength situation [25]. Confirmation of this strength ratio for any composite through more detailed studies would be of great importance, because tensile and flexural specimens are of great different sizes. Less expensive flexural specimens are easier to test and could then be used to estimate ultimate tensile stresses of composite materials for preliminary design purposes. Even though the studies reported on such strength comparisons are less, from the data available such comparisons can be made. $\mathrm{Ku}$ and Wong [26] observed that flexural strengths of hollow-glass microspheres filled epoxy composites are nearly three times of tensile strengths up to $10 \mathrm{wt} \%$ of glass powder reinforcement. Lin et al. [27] observed that bending strengths of $\mathrm{PEEK} / \mathrm{CaCO}_{3}$ composites lied in the range of 1.90-2.10 times of tensile strengths, when the whisker content was varied from 0 to $45 \mathrm{wt} \%$. In the present study, this strength ratio is found to lie in the range of 1.93-2.02. However, this ratio decreased slightly with the increase in the PTW content.

3.1.4. Impact Strength. From Table 3, it is clear that impact strength of all composites is less than that of pristine epoxy and reinforcement of PTW with the epoxy was not beneficial in improving the impact resistance of the neat polymer. The notable loss (a drop of 13\%) in the impact strength of the epoxy/PTW composites can be attributed to the poor interfacial bonding between whisker and the polymer matrix on account of impact force. From the impact results, it is clear that high aspect ratio filler particles which have imparted stiffness in a composite inevitably caused increased stress in the polymer matrix near particle edges that facilitated failure under impact loads. Typically, a polymer matrix with loading of fillers has less ability to absorb impact energy. Fillers disturb the matrix continuity and individual filler is a site of stress concentration, which can act as a microcrack initiator [28]. As flexural and tensile strength properties, Izod impact strength of composites decreased with substitution of PTW in the epoxy; however, differences are not significant.

Epoxy-based composites are known to be highly susceptible to internal damage caused by a low velocity impact due to inherent brittleness of the cured resin, which may lead to severe safety and reliability problems. Thus, for high performance applications the improvement of damage tolerance of epoxy composites by enhancing their impact strength is essential and has been the subject of investigation throughout the world. This problem can be overcome by using the additional phase toughening technology where the modifier is incorporated as a separate phase. Depending on the additional phase used, epoxy toughening can be grouped into four types: liquid rubber toughening, core-shell particle toughening, thermoplastic toughening, and rigid particle toughening [29]. 
3.1.5. Morphology of Tensile Fractured Surfaces. Figures 6(a) to $6(d)$ show the tensile fracture surfaces of the composites at different whisker loadings. River line markings (marked as AA) followed by a "turbulent flow" can be observed on the fractured surface of the neat epoxy specimen [26]. This shows that plastic deformation has taken place in the resin. SEM pictures revealed more filler particles with the increase in whisker loadings. At a whisker loading of $5 \mathrm{wt} . \%$ only a few whiskers are seen and composite mainly represents the plastic deformation. An inclusion (marked as B) on the fractured surface after the tensile test appears as a bright spot as illustrated in the Figure 6(b). This is mainly due to the common problem of "charging" under SEM examination which is often associated with the loose debris on the fractured surface [30]. At higher whisker loading (Figures 6(c) and 6(d)) holes, whiskers pulled-out traces (marked as circles) are seen. At $15 \mathrm{wt} \%$ filler loading (Figure 6(d)), more whisker particles are seen and the large amount of poor bonded interfacial area between whisker and epoxy matrix causes brittle deformation of the composite. Upper left corner in Figure 6(d) shows a layer of epoxy overlapping, which is the result of plastic deformation of the matrix material. It can be seen that some of the whiskers are not removed from the matrix, which can be attributed to existence of the bond between the whisker and the epoxy matrix. Under uniaxial straining, whisker debonding and pull-out and brittle fracture of the matrix have been found to govern the failure of epoxy/PTW composites.

The observed trend in the mechanical properties of epoxy/PTW composites is in line with the published findings reported in case of particulate filled epoxy composites. However, the extent of variation in properties differed in the present investigation and can be attributed to the whisker size and loading being different in the current study [31].

\subsection{Tribological Properties}

3.2.1. Coefficient of Friction (COF). Variation of the COF for different test specimens is illustrated in Table 4 . The standard deviation of each value in Table 4 is varied between 0.020 and 0.070 . It can be observed that COF decreases with load for all material combinations for given sliding velocity and it increases with filler content for all loading conditions. However, COF showed varying trend with respect to different sliding velocities for all material combinations. All readings reported in Table 4 are taken after 10 minutes (run-in-time) of starting the test. With the addition of the PTW, friction coefficient of the composites has increased. It is implicit that in case of polymers sliding against metallic counterparts, the friction component resulting from adhesion is equal to product of real contact area and the shear stress of the polymer material. However, in case of filled polymers, friction depends upon both adhesion and abrasion. PTW always increases the abrasive force and decreases the real contact area during the friction processes [32]. Therefore, friction coefficient has shown a growing trend with the increasing of PTW content.

Figure 7 shows the variation of COF versus sliding time for different test samples for $0.5 \mathrm{~m} / \mathrm{s}$ sliding velocity and under $30 \mathrm{~N}$ load. It can be seen that composites have better friction stability than the matrix. Moreover, small whisker content ( $5 \mathrm{wt} \%$ and $10 \mathrm{wt} \%$ ) could greatly improve the friction stability $(0.45-0.50)$ of the matrix which could be clearly observed from the Figure 7 . The COF values are also found to be highly reproducible within $3 \%$ in the steady state period. Such smooth frictional fluctuations in case of PTW reinforced with other thermoset matrices such as phenolic resin and bismaleimide resin are also reported in the literatures $[16,33]$. However, values of COF obtained and extending of variation in the current study are different, which is mainly because of different matrix material and sliding conditions considered in the present test. It is understandable that change in the sliding conditions has a direct influence on the frictional behavior of the epoxy/PTW composites. It is evident that friction coefficient reduces drastically with the increase in the normal load from $10 \mathrm{~N}$ to $30 \mathrm{~N}$ (Table 4). This is an expected behavior which is also presented in (2) that friction coefficient is inversely proportional to normal load. It can also be observed that friction coefficient is sliding velocity and distance dependent. It is generally accepted that increase in the sliding velocity or sliding distance results in the thermal softening of the polymer matrix material. This thermal softening of the matrix material exposes the PTW fillers at the interface and further increases of the velocity/distance detach the ceramic fillers from the parent material and these whiskers act as third body [34] and are mainly responsible for oscillatory character of friction coefficient. The rolling effect of ceramic fillers under dry sliding conditions that leads to low friction and wear in case of polymer composites is debated in literatures [25, 28]. However, PTW particles have less tendency to roll and more prone to slide, mainly because of their morphology (Figure 1) as they are not spherical and have sharp corners. Thus it can be inferred that sliding friction has a significant effect in the present case and whereas, the effect of rolling friction which can be easily attained in case of spherical particles and smooth mating surfaces is comparatively less. This sliding friction increases with the increasing amount of PTW, mainly because of abrasion, and increases COF values. Thus both adhesion and abrasion describe the friction in case of epoxy/PTW composites. The proportion of adhesion to abrasion also changes due to the presence of epoxy debris at the sliding interface and the change in sliding conditions such as velocity and distance. The actual friction coefficient can be explained by a superposition of these two mechanisms.

3.2.2. Specific Wear Rate $\left(W_{s}\right)$. The specific wear rate of test samples as a function of load, distance, and speed, respectively, are shown in Figures 8-10. Apparently, pure epoxy exhibits highest wear rate, whereas epoxy/PTW composites exhibit lower wear rate for the given set of applied load, sliding distance, and sliding velocity employed. As there is no barrier to wear, pure epoxy resin shows highest wear rate. However, lower wear rate in reinforced samples indicates that ceramic whiskers effectively prevent the wear of the epoxy matrix. Epoxy/PTW composites show a decrease in the wear rate with the increase in the content of PTW reinforcement, 


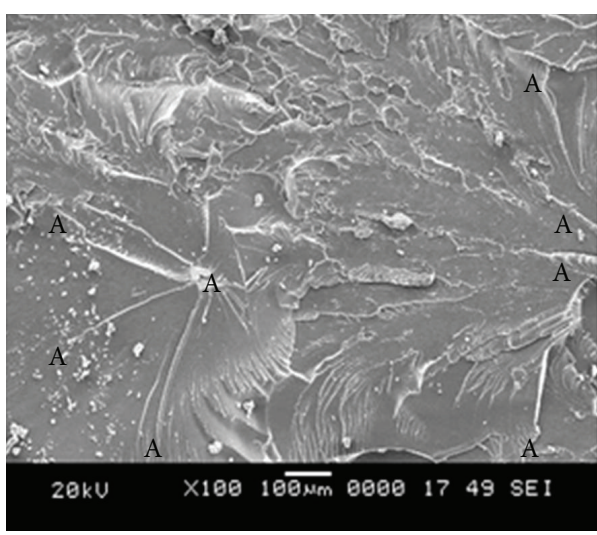

(a)

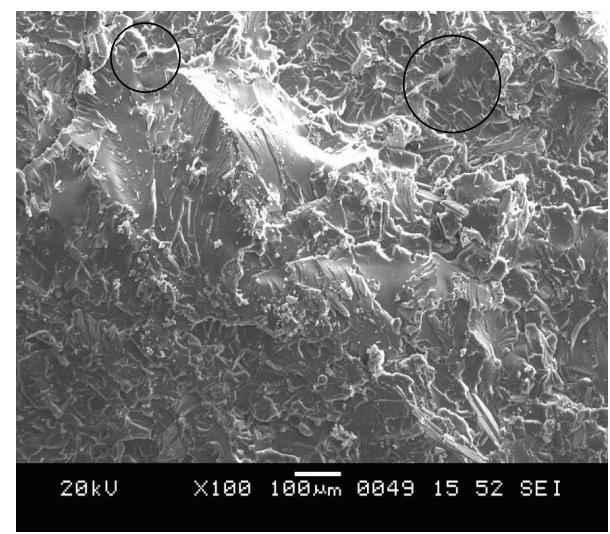

(c)

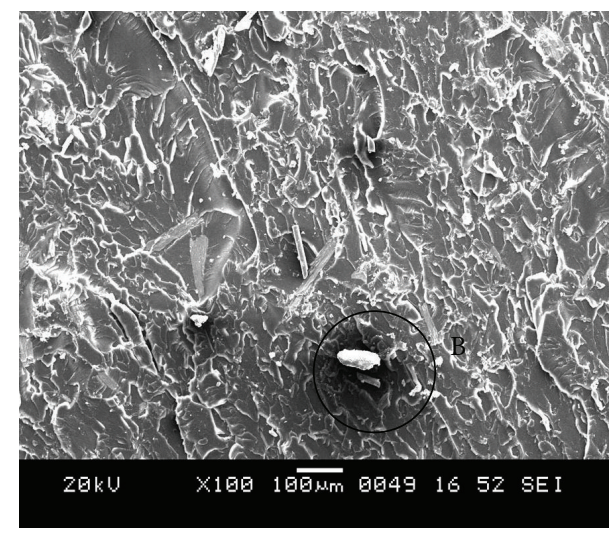

(b)

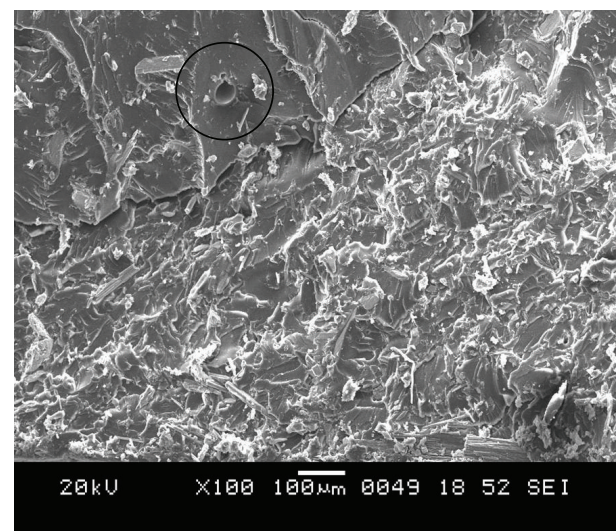

(d)

Figure 6: SEM pictures of tensile fractured surfaces. (a) EP0, (b) EP5, (c) EP10, and (d) EP15 samples.

TABLE 4: COF for test samples under different loads and velocities.

\begin{tabular}{|c|c|c|c|c|c|c|c|c|c|}
\hline \multirow{3}{*}{ Material } & \multicolumn{9}{|c|}{ Coefficient of friction (COF) } \\
\hline & \multicolumn{3}{|c|}{ Velocity $0.5 \mathrm{~m} / \mathrm{s}$} & \multicolumn{3}{|c|}{ Velocity $0.75 \mathrm{~m} / \mathrm{s}$} & \multicolumn{3}{|c|}{ Velocity $1 \mathrm{~m} / \mathrm{s}$} \\
\hline & $10 \mathrm{~N}$ & $20 \mathrm{~N}$ & $30 \mathrm{~N}$ & $10 \mathrm{~N}$ & $20 \mathrm{~N}$ & $30 \mathrm{~N}$ & $10 \mathrm{~N}$ & $20 \mathrm{~N}$ & $30 \mathrm{~N}$ \\
\hline EP0 & 0.620 & 0.510 & 0.420 & 0.620 & 0.505 & 0.380 & 0.590 & 0.475 & 0.480 \\
\hline EP5 & 0.670 & 0.530 & 0.500 & 0.620 & 0.495 & 0.427 & 0.590 & 0.545 & 0.493 \\
\hline EP10 & 0.690 & 0.540 & 0.493 & 0.660 & 0.510 & 0.453 & 0.690 & 0.540 & 0.493 \\
\hline EP15 & 0.720 & 0.545 & 0.498 & 0.690 & 0.545 & 0.480 & 0.780 & 0.590 & 0.496 \\
\hline
\end{tabular}

which acts as obstacle to shear deformation during the sliding conditions. With a rise in the concentration of whiskers the declining trend in the wear rate is significant. It can be clearly inferred that EP15 composites suffered lowest damage during wear tests. Thus PTW is found to enhance the wear resistance (inverse of wear rate) property of the epoxy polymer. Specific wear rate of EP15 composites is reduced by nearly $48 \%$ compared to that of neat epoxy under maximum sliding conditions considered in the test. Following Figure 8, it can be seen that maximum reduction in the wear rate observed is about $64 \%$ and is under a load of $10 \mathrm{~N}$.

Referring to Figures 8 and 9, it can be observed that increase in the normal load and sliding distance contributes to the reduction of the wear rate values for all material compositions. As mentioned earlier, PTW fillers easily detach from the epoxy matrix due to the plastic deformation under the influence of normal load and sliding distance. Thus there is a large amount of transfer material between the two mating partners and it forms the tribofilm at the interface [35]. This transfer film protects the composite material from abrasion and is responsible for decrease in the specific wear rate. Also, the compacted tribofilms could more effectively protect the composite material from abrasion [36]. Consequently, the specific wear rate showed reductive tendencies with the increase of normal load and sliding distance. For the EP15 composites, wear rate values do not seem to be affected much by the change in the applied load (Figure 8). Specific wear rate did not change appreciably for the normal load considered which means that volumetric loss per unit load and unit distance remained almost constant. No change in 


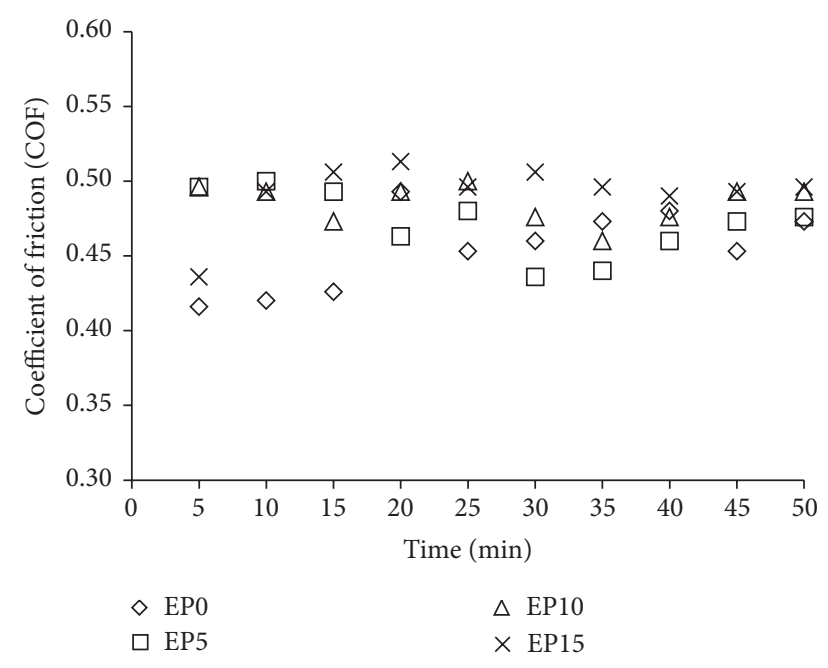

FIGURE 7: Variation of COF with sliding time (min).

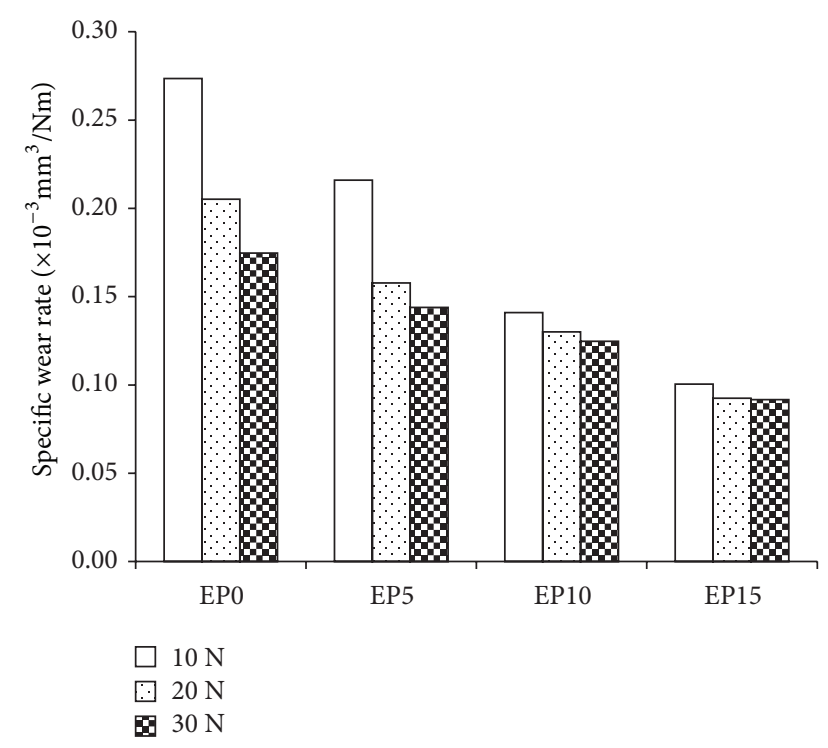

FIGURE 8: Variations of the specific wear rate with respect to normal load for different material compositions $(1 \mathrm{~m} / \mathrm{s}, 1500 \mathrm{~m})$.

wear mechanism with load could be the reason for this trend.

The specific wear rate showed increasing trend with the increase in sliding velocity (Figure 10). The reason is that the increase in the sliding velocity increases the rubbing action at the interface and increases the wear rate. The increase in the wear rate observed is $26 \%$ for $\mathrm{EP}$ and $19 \%$ for EP15 specimens when the sliding speed was increased by $100 \%$. Thus increase in the wear rate with the sliding speed is only marginal. Ozturk et al. [37] reported that an increase in the sliding speed increases the rate of impact type loading caused by the hard asperities present on the counterface. This increases the frictional thrust, which in turn causes localized vibration and chattering at the sliding interface, thereby increasing the fracture of the matrix and debonding the fillers. These fillers

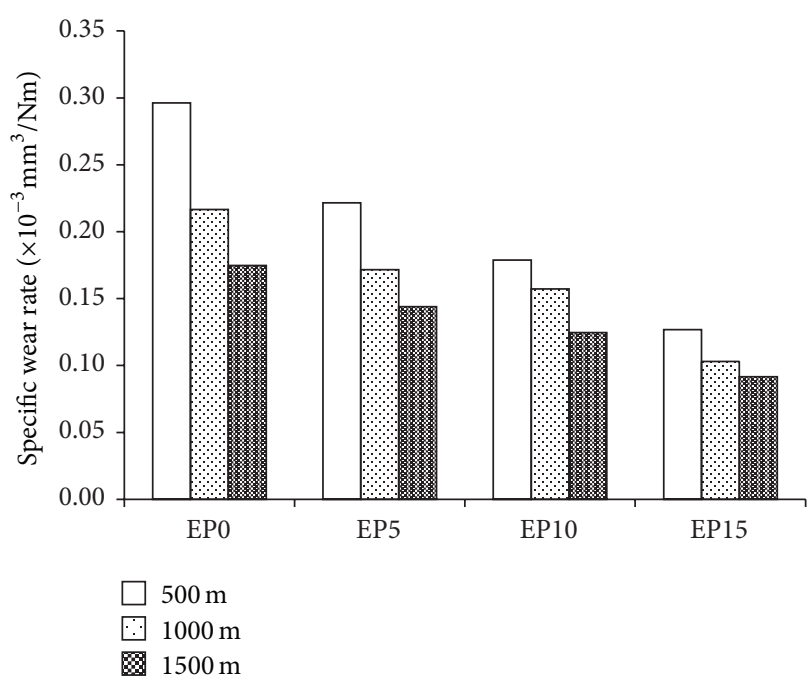

FIGURE 9: Variations of the specific wear rate with respect to sliding distance for different material compositions $(30 \mathrm{~N}, 1 \mathrm{~m} / \mathrm{s})$.

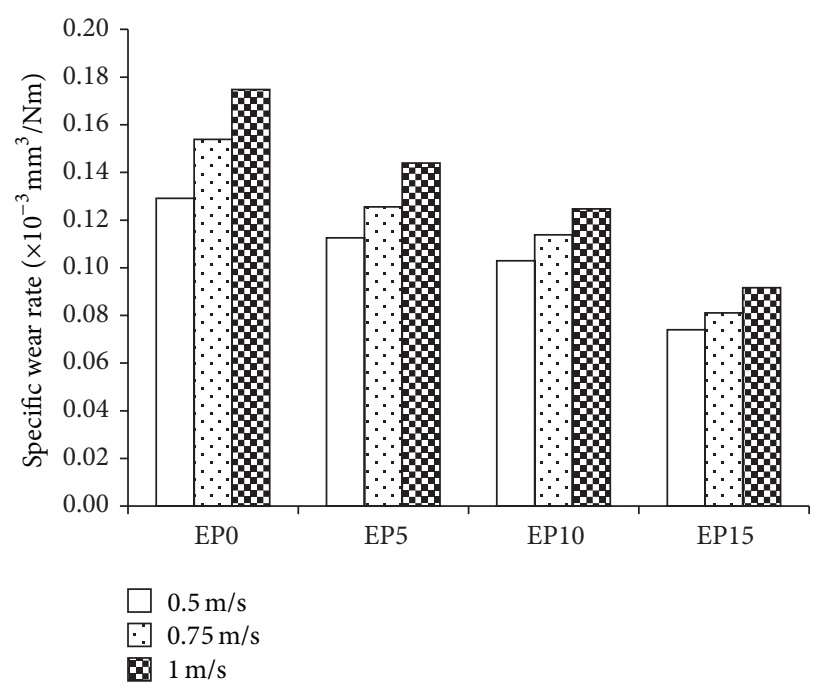

FIGURE 10: Variations of the specific wear rate with respect to sliding velocity for different material compositions $(30 \mathrm{~N}, 1500 \mathrm{~m})$.

act to increase the wear rate of the specimen by damaging the counterface film. It is well known that wear processes involve fracture, tribochemical effects, and plastic flow. Transitions between regions dominated by each of these commonly lead to changes in specific wear rate with applied load and sliding speed. Moreover, this result is closely related to structural characteristics, and chemical effects occurred in frictional processes as well as transfer film formation on the counterface [38]. As already mentioned, higher COF was measured for the epoxy/PTW composites as a result of good cutting resistance of whiskers. The temperature at the pin and disc interface increased due to the frictional heating. Owing to the higher heat resistance of whiskers, composites could reserve more mechanical strength under high temperature. Consequently, materials were not easily peeled off any more like pure epoxy, 
and lower wear rates were thus obtained for epoxy/PTW composites.

The lowest specific wear rate from wear plots is $0.09 \times$ $10^{-3} \mathrm{~mm}^{3} / \mathrm{Nm}$ and is in the case of EP15 composite under maximum sliding conditions. Comparing this performance with that of boron carbide filled epoxy [3], it has been reported that specific wear rate lied in the range of 1.1-2.0 $\times$ $10^{-3} \mathrm{~mm}^{3} / \mathrm{Nm}$ under comparatively lower sliding conditions $(15 \mathrm{~N}, 1000 \mathrm{~m}$, and $180 \mathrm{rpm})$ on pin-on-disc test rig. This poor performance of boron carbide filled epoxy even at lower concentration of fillers ( 6 and $12 \mathrm{wt} \%$ ) can be attributed to the abrasive nature of harder filler during dry sliding. A lower percentage of PTW (5 wt\%) in case of bismaleimide resin [33] has shown comparatively lower wear rate of $1.03 \times$ $10^{-6} \mathrm{~mm}^{3} / \mathrm{Nm}$ when tested on pin-on-disc at different sliding conditions $(196 \mathrm{~N}, 0.24 \mathrm{~m} / \mathrm{s}$, and $120 \mathrm{~min})$. The best wear resistance of bismaleimide matrix at small percentage of PTW is mainly due to silane treatment of whiskers before blending with matrix. However, with the PTFE as matrix material a very low wear rate of the order of $10^{-7} \mathrm{~mm}^{3} / \mathrm{Nm}$ is observed at loading of $20 \mathrm{wt} \%$ of PTW under dry sliding [32]. Such a low wear rate is mainly due to lubricating nature of bulk matrix material during sliding. The silane treatment of PTW before mixing with epoxy resin is expected to further improve the performance of epoxy/PTW composites and research in this direction is currently planned.

3.2.3. Worn Surface Morphology. Key evidence on the wear mechanism operative is obtained on the worn surface of the specimens after sliding against the steel counterpart. Figures 11(a)-11(d) show the SEM pictures of worn surface of the specimens tested at maximum sliding conditions. The white arrow on the lower left corner of the SEM picture indicates the sliding direction. From Figure 11(a), it is clear that neat epoxy has undergone the severe damage under the dry sliding conditions. Large wear debris left over the surface of the epoxy specimen can be seen. This debris appears to have been mainly produced by the large scale fragmentation of the epoxy matrix. Matrix cracking in the direction perpendicular to the sliding and plastic deformation of the matrix is also found on the worn surface. These mechanisms of material loss are responsible for high wear rate of neat epoxy. Large scale detachment of the matrix material has left several cavities on the epoxy specimen, indicating that fatigue wear is the dominant mechanism accountable for the high wear rate. An analogous situation has been reported by Bassani et al. [39] in case of epoxy sliding over inox steel under dry sliding conditions.

Microploughing furrows and wear tracks parallel to sliding direction are observed on the surface of the composite specimen (Figures 11(b)-11(d)). Under the high applied load, PTW particles detach from the matrix and result in abrasive action between the two mating surfaces (Figure 11(c)). These loose particles change the mechanism from two-body abrasion to three-body abrasion and act to protect the matrix material resulting in lower wear rate. PTW particles exposed on the worn surface are clearly visible in the SEM pictures (Figures 11(b) and 11(c)). It was observed during the study

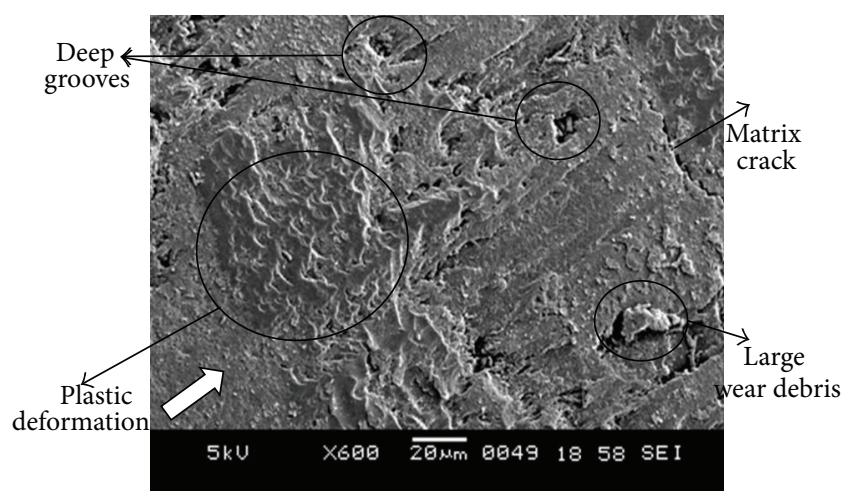

(a)

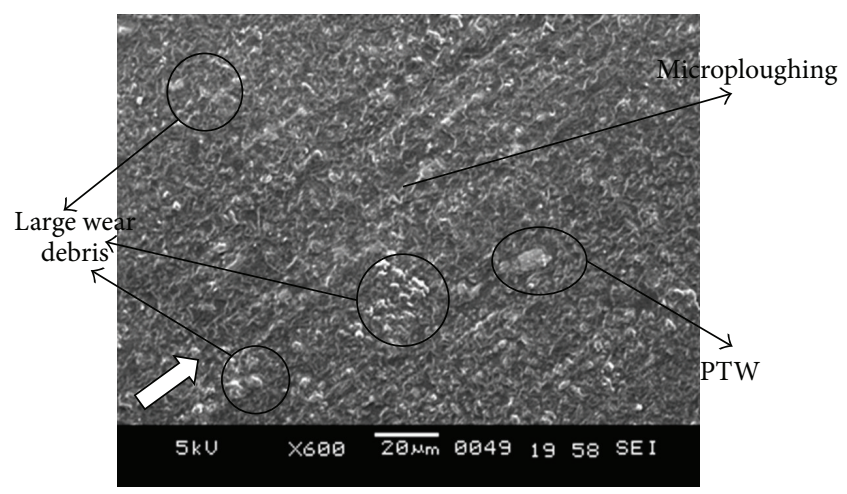

(b)

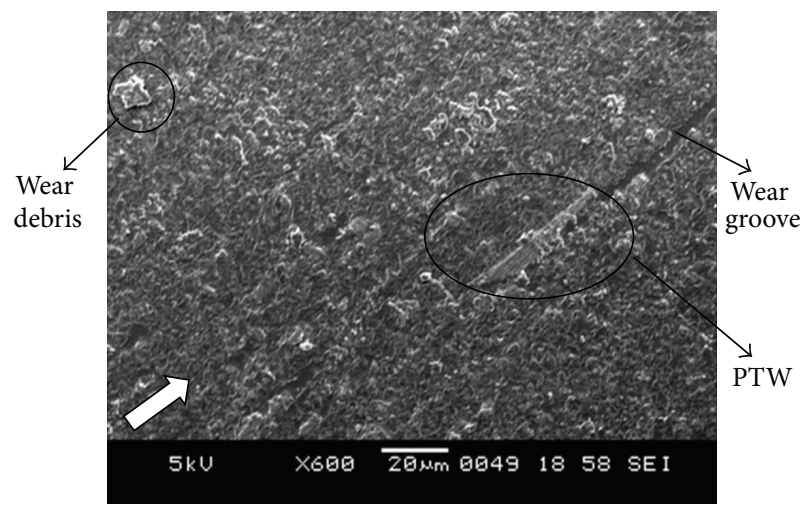

(c)

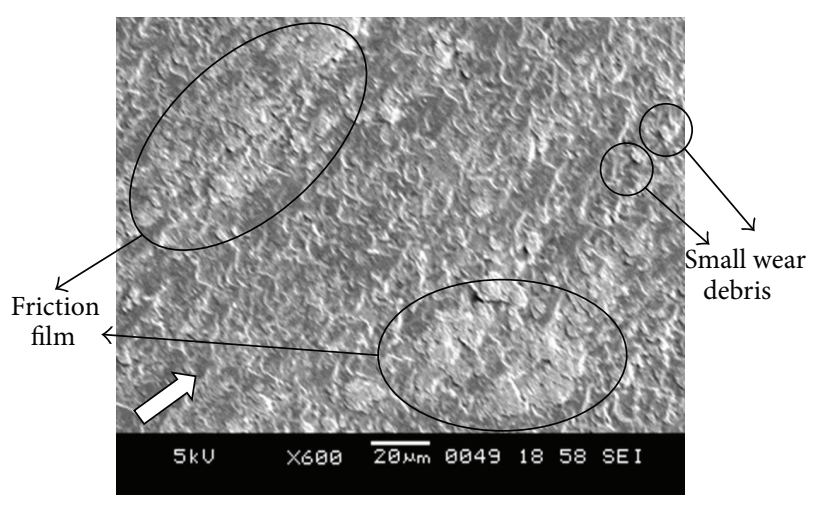

(d)

FIGURE 11: SEM pictures of worn-out surfaces.(a) EP0, (b) EP5, (c) EP10, and (d) EP15 samples (test conditions: load $30 \mathrm{~N}$, speed $1 \mathrm{~m} / \mathrm{s}$, and distance $1500 \mathrm{~m}$ ). 
that friction increases with the PTW content. This increase in the friction results in the heating effect, which promotes the temperature rise and hence softening of the polymer surface, forming a thin visible film on the disc surface [35]. Some patches of this friction film on the composite surface can be observed in Figure 11(d). As a result of the formation of the friction layer between the mating surfaces, the microploughing and microcracking became slight and the tribological properties are improved. Small wear debris observed on the surface of the EP15 is an indication of the wear resistant material. It can be inferred from the micrographs that both adhesive and abrasive wear mechanisms are operative in case of epoxy/PTW composites. However, depending on each material combination and the different testing parameters, the proportion of adhesive to abrasive changes [40]. The patterns observed for specific wear rate of the composites correlate well with the SEM analysis of surface morphology.

\section{Conclusions}

Epoxy/PTW composites with various contents of PTW were processed and studied. Mechanical and dry sliding wear tests were conducted to investigate the effect of PTW on the effective properties of epoxy/PTW composites. From the experimental results, the following conclusions can be made.

(1) PTW additions were beneficial in improving the tensile and flexural modulus of epoxy. Besides, a slight improvement in density and hardness of epoxy was also found. However strain to break and strength of epoxy under tensile and flexural and impact loading were found to suffer with whisker loading.

(2) Examination of tensile fractured surfaces suggested that brittle failure of matrix and whisker pull-out were two dominant failure mechanisms.

(3) Tribological tests revealed stable friction coefficients and lower wear rates of PTW filled composites for selected sliding conditions.

(4) Worn-out surface features revealed fatigue wear as leading mechanism in case of neat epoxy and microploughing, abrasion, and adhesion as acting mechanisms in case of epoxy/PTW composites.

In summary, PTW can be used as good reinforcing filler for thermoset polymers such as epoxy. However, a compromise is essential in deciding the content of PTW so as not to sacrifice too much of its strength and ductility.

\section{Conflict of Interests}

The authors declare that there is no conflict of interests regarding the publication of this paper.

\section{Acknowledgments}

The authors extend thanks and appreciations to the director, principal, and vice principal of St. Joseph Engineering College, Mangalore, India, for their support and encouragement to carry out this research work. Thanks are also due to $\mathrm{M} / \mathrm{s}$ Brakes India, Mysore, for providing mechanical testing facilities, Metallurgy and Material Science Engineering Department at NITK Surathkal, India, for SEM facilities, and GTTC, Mangalore, India, for technical support.

\section{References}

[1] R. M. Wang, S. R. Zheng, and Y. P. Zheng, Polymer Matrix Composites and Technology, Woodhead Publishing Limited (Science Press), Cambridge, UK, 2011.

[2] S. Y. Fu, B. Lauke, and Y. W. Mai, Science and Engineering of Short Fibre Reinforced Polymer Composites, Woodhead Publishing Limited (CRC Press), Cambridge, UK, 2009.

[3] J. Abenojar, M. A. Martínez, F. Velasco, V. Pascual-Sánchez, and J. M. Martín-Martínez, "Effect of boron carbide filler on the curing and mechanical properties of an epoxy resin," Journal of Adhesion, vol. 85, no. 4-5, pp. 216-238, 2009.

[4] M. S. Bhagyashekar and R. M. V. G. K. Rao, "Effects of material and test parameters on the wear behavior of particulate filled composites part 1: SiC-epoxy and Gr-epoxy composites," Journal of Reinforced Plastics and Composites, vol. 26, no. 17, pp. 1753-1768, 2007.

[5] G. Shi, M. Q. Zhang, M. Z. Rong, B. Wetzel, and K. Friedrich, "Sliding wear behavior of epoxy containing nano- $\mathrm{Al}_{2} \mathrm{O}_{3}$ particles with different pretreatments," Wear, vol. 256, no. 11-12, pp. 1072-1081, 2004.

[6] O. Jacobs, R. Jaskulka, F. Yang, and W. Wu, "Sliding wear of epoxy compounds against different counterparts under dry and aqueous conditions," Wear, vol. 256, no. 1-2, pp. 9-15, 2004.

[7] X. Li, Y. Gao, J. Xing, Y. Wang, and L. Fang, "Wear reduction mechanism of graphite and $\mathrm{MoS}_{2}$ in epoxy composites," Wear, vol. 257, no. 3-4, pp. 279-283, 2004.

[8] Q. L. Ji, M. Q. Zhang, M. Z. Rong, B. Wetzel, and K. Friedrich, "Friction and wear of epoxy composites containing surface modified SiC nanoparticles," Tribology Letters, vol. 20, no. 2, pp. 115-123, 2005.

[9] D. D. Rodrigues and J. G. Broughton, "Silane surface modification of boron carbide in epoxy composites," International Journal of Adhesion \& Adhesives, vol. 46, pp. 62-73, 2013.

[10] S. Shokoohi, A. Arefazar, and R. Khosrokhavar, "Silane coupling agents in polymer-based reinforced composites: a review," Journal of Reinforced Plastics and Composites, vol. 27, no. 5, pp. 473-485, 2008.

[11] P. C. Ma, J. Kim, and B. Z. Tang, "Effects of silane functionalization on the properties of carbon nanotube/epoxy nanocomposites," Composites Science and Technology, vol. 67, no. 14, pp. 2965-2972, 2007.

[12] D. I. Tee, M. Mariatti, A. Azizan, C. H. See, and K. F. Chong, "Effect of silane-based coupling agent on the properties of silver nanoparticles filled epoxy composites," Composites Science and Technology, vol. 67, no. 11-12, pp. 2584-2591, 2007.

[13] J. V. Milewski and H. S. Katz, "Whiskers," in Handbook of Reinforcements for Plastics, pp. 205-229, Van Nostrand Reinhold, New York, NY, USA, 1987.

[14] T. Zaremba and D. Witkowska, "Methods of manufacturing of potassium titanate fibres and whiskers. A review," Materials Science-Poland, vol. 28, no. 1, pp. 25-41, 2010.

[15] Z. Zhu, L. Xu, and G. Chen, "Effect of different whiskers on the physical and tribological properties of non-metallic friction materials," Materials and Design, vol. 32, no. 1, pp. 54-61, 2011. 
[16] S. J. Kim, M. H. Cho, R. H. Basch, J. W. Fash, and H. Jang, "Tribological properties of polymer composites containing barite $\left(\mathrm{BaSO}_{4}\right)$ or potassium titanate $\left(\mathrm{K}_{2} \mathrm{O} .6\left(\mathrm{TiO}_{2}\right)\right)$," Tribology Letters, vol. 17, no. 3, pp. 655-661, 2004.

[17] K. H. Cho, M. H. Cho, S. J. Kim, and H. Jang, "Tribological properties of potassium titanate in the brake friction material; morphological effects," Tribology Letters, vol. 32, no. 1, pp. 5966, 2008.

[18] X. Feng, H. Wang, Y. Shi, D. Chen, and X. Lu, "The effects of the size and content of potassium titanate whiskers on the properties of PTW/PTFE composites," Materials Science and Engineering A, vol. 448, no. 1-2, pp. 253-258, 2007.

[19] S. Chen, Q. Wang, T. Wang, and X. Pei, "Preparation, damping and thermal properties of potassium titanate whiskers filled castor oil-based polyurethane/epoxy interpenetrating polymer network composites," Materials and Design, vol. 32, no. 2, pp. 803-807, 2011.

[20] M. Sudheer, R. Prabhu, K. Raju, and T. Bhat, "Optimization of dry sliding wear performance of ceramic whisker filled epoxy composites using Taguchi approach," Advances in Tribology, vol. 2012, Article ID 431903, 9 pages, 2012.

[21] I. Taha, A. El-Sabbagh, and G. Ziegmann, "Modelling of strength and stiffness behaviour of natural fibre reinforced polypropylene composites," Polymers and Polymer Composites, vol. 16, no. 5, pp. 295-302, 2008.

[22] A. Patnaik, A. Satapathy, S. S. Mahapatra, and R. R. Dash, "A comparative study on different ceramic fillers affecting mechanical properties of glass polyester composites," Journal of Reinforced Plastics and Composites, vol. 28, no. 11, pp. 1305-1318, 2009.

[23] L. Nielsen and R. Landel, Mechanical Properties of Polymers and Composites, Marcel Decker, New York, NY, USA, 2nd edition, 1994.

[24] M. Qu, X. Jian, W. He, and G. Liao, "Performance of potassium titanate whisker reinforced PPESK composites," Journal of Materials Science and Technology, vol. 20, no. 4, pp. 445-447, 2004.

[25] K. Friedrich, S. Fakirov, and Z. Zhang, Polymer Composites from Nano- to Macroscale, Springer, New York, NY, USA, 2005.

[26] H. Ku and P. Wong, "Contrast on tensile and flexural properties of glass powder reinforced epoxy composites: pilot study," Journal of Applied Polymer Science, vol. 123, no. 1, pp. 152-161, 2012.

[27] Y. Lin, C. Gao, and N. Li, "Influence of $\mathrm{CaCO}_{3}$ whisker content on mechanical and tribological properties of polyetheretherketone composites," Journal of Materials Science and Technology, vol. 22, no. 5, pp. 584-588, 2006.

[28] R. N. Rothon, Particulate Filled Polymer Composites, Rapra Technology, London, UK, 2nd edition, 2003.

[29] D. Ratna, "Epoxy composites: impact resistance and flame retardancy, volume 16, number 5," Rapra Review Reports 185, Smithers Rapra Technology, London, UK, 2005.

[30] E. S. Greenhalgh, Failure Analysis and Fractography of Polymer Composites, Woodhead Publishing Limited (CRC Press), Cambridge, UK, 2009.

[31] S. Y. Fu, X. Q. Feng, B. Lauke, and Y. W. Mai, "Effects of particle size, particle/matrix interface adhesion and particle loading on mechanical properties of particulate-polymer composites," Composites B: Engineering, vol. 39, no. 6, pp. 933-961, 2008.

[32] X. Feng, X. Diao, Y. Shi, H. Wang, S. Sun, and X. Lu, "A study on the friction and wear behavior of polytetrafluoroethylene filled with potassium titanate whiskers," Wear, vol. 261, no. 11-12, pp. 1208-1212, 2006.

[33] G. Liang, H. U. Xiaolan, and L. U. Tingli, "Inorganic whiskers reinforced bismaleimide composites: part II the tribological behavior of BMI/potassium titanate composites," Journal of Materials Science, vol. 40, no. 7, pp. 1743-1748, 2005.

[34] W. Österle, I. Dörfel, C. Prietzel et al., "A comprehensive microscopic study of third body formation at the interface between a brake pad and brake disc during the final stage of a pin-on-disc test," Wear, vol. 267, no. 5-8, pp. 781-788, 2009.

[35] S. Bahadur, "The development of transfer layers and their role in polymer tribology," Wear, vol. 245, no. 1-2, pp. 92-99, 2000.

[36] G. Straffelini, M. Pellizzari, and A. Molinari, "Influence of load and temperature on the dry sliding behaviour of Al-based metal-matrix-composites against friction material," Wear, vol. 256, no. 7-8, pp. 754-763, 2004.

[37] B. Ozturk, F. Arslan, and S. Ozturk, "Hot wear properties of ceramic and basalt fiber reinforced hybrid friction materials," Tribology International, vol. 40, no. 1, pp. 37-48, 2007.

[38] H. Unal, U. Sen, and A. Mimaroglu, "An approach to friction and wear properties of polytetrafluoroethylene composite," Materials and Design, vol. 27, no. 8, pp. 694-699, 2006.

[39] R. Bassani, G. Levita, M. Meozzi, and G. Palla, "Friction and wear of epoxy resin on inox steel: remarks on the influence of velocity, load and induced thermal state," Wear, vol. 247, no. 2, pp. 125-132, 2001.

[40] L. Chang and K. Friedrich, "Enhancement effect of nanoparticles on the sliding wear of short fiber-reinforced polymer composites: a critical discussion of wear mechanisms," Tribology International, vol. 43, no. 12, pp. 2355-2364, 2010. 

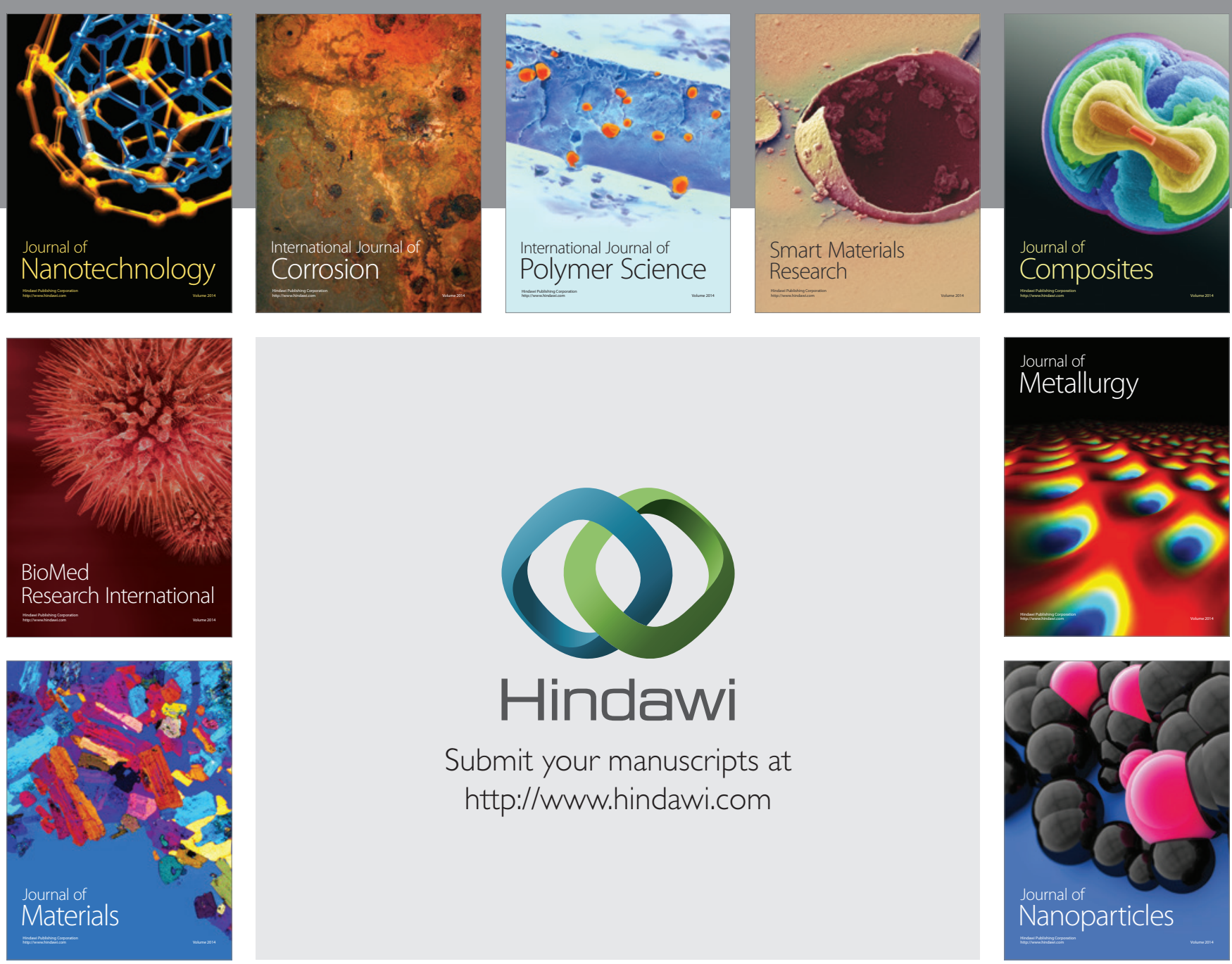

Submit your manuscripts at http://www.hindawi.com
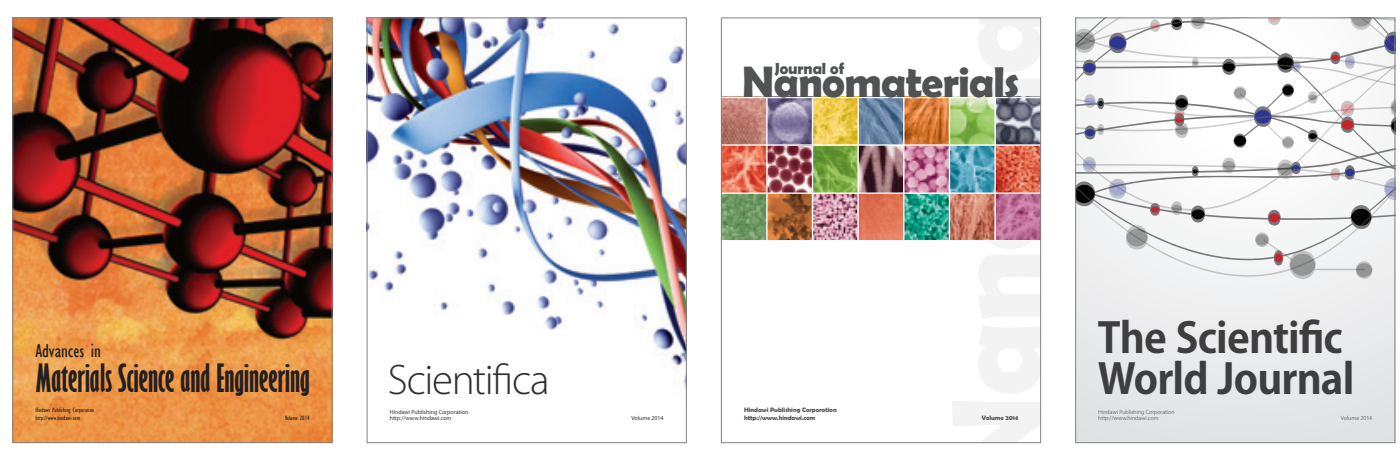

\section{The Scientific World Journal}
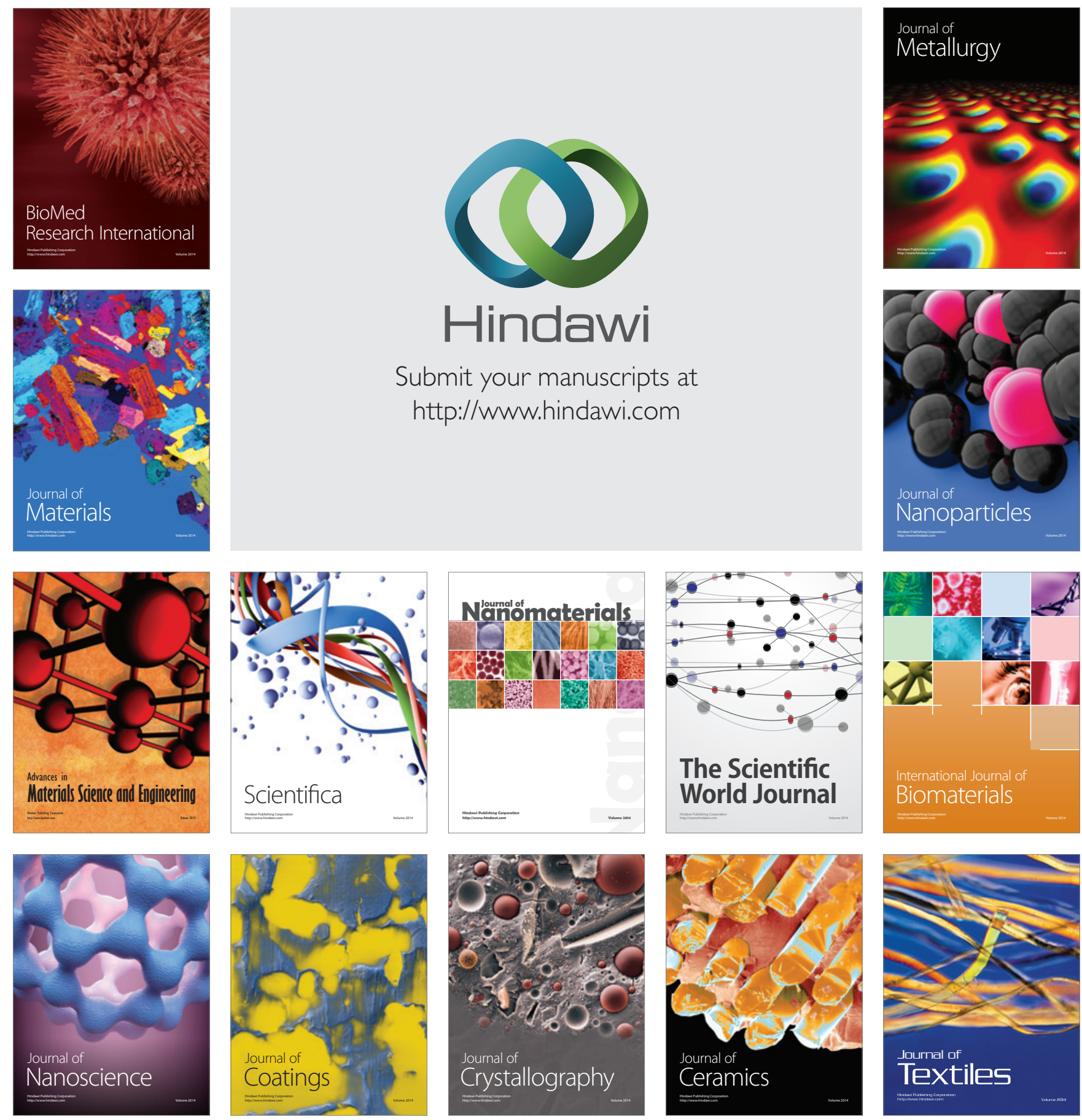